\title{
Development of Equipment for Reinforcement of Road Surfaces by Means of Hydrojet Cementation
}

\author{
Konstantin Alexandrovich Golovin ${ }^{1}$, Roman Anatolievich Kovalev ${ }^{1}$, Julia Nikolaevna Pushilina ${ }^{1} \&$ Igor \\ Vladimirovich Afonskiy ${ }^{1}$ \\ ${ }^{1}$ Federal State-Funded Educational Institution of Higher Professional Education "Tula State University", Russia \\ Correspondence: Roman Anatolievich Kovalev, Federal State-Funded Educational Institution of Higher \\ Professional Education "Tula State University", 92, Lenin prospect, Tula, Russia. E-mail: \\ kovalevdekan@mail.ru
}

Received: October 15, 2014

doi:10.5539/mas.v9n2p61

\author{
Accepted: October 25, $2014 \quad$ Online Published: December 7, 2014 \\ URL: http://dx.doi.org/10.5539/mas.v9n2p61
}

\begin{abstract}
In building equipment there are machines using waterjet cementation (WJC) of rock to create cement rock constructions of different purposes. This technology is useful for road construction. The article includes data on mathematical modeling of waterjet cementation. The results of the mathematical modeling are used to adjust the waterjet cementation technology for the strengthening of road surface or other plane surface objects. Reinforcement of road surface can be carried out with jet-forming device, being placed directly at the subsoil surface or at some distance from the surface. The article provides a constructional description of the machine for strengthening the road surface with waterjet cementation method and also gives recommendations for determining its efficient operation modes. Waterjet cementation equipment for road surfaces allows significant simplification of modern major highway construction technology.
\end{abstract}

Keywords: High-speed jet, jet cementation, soil concrete, road bed, rock, depth of restraint, performance, storage density

\section{Introduction}

Development of technologies, based on using high-speed jets as the means of rock processing, is now one of the most prospective areas of mining (Brenner et al, 2007; Nikonov et al, 2006; Hashish, 1998; Brenner et al, 1998; Sammers, 1995). High-speed jets' ability to cut rock of any hardness, relative simplicity of technological process organization, during which the jets take the functions of saturating the material, being destroyed, with linking additives, mixing destruction products, as well as the high speed cutting when there is no digging face reaction on the instrument makes them attractive from the point of view of realization of executive parts of mining machinery in the construction for the formation of rock masses with physical and mechanical properties. This circumstance served as the reason for the recent appearance of a great amount of machinery on the building market, using waterjet cementation (WJC) of rocks to create concrete rock constructions of different purposes. Development of mining equipment, realizing waterjet cementation of rock mass allows significant simplification of drivage in unstable rocks, making it safer and helping to find more effective alternative to the other known methods of rock masses' restraint.

\section{Method}

\subsection{Design Model Technology for Hydraulic Destruction of Rocks by Means of Water Cement Submerged Jets}

2.1.1 Brief Analysis of Design Models for Hydraulic Destruction of Rocks by Means of Water Cement Submerged Jets

To describe the interaction between high pressure hydraulic jets and known types of rock we use different methods, combination of which can be divided into three groups: theoretical, empirical and semi-empirical. The first one is usually based on solving interrelated problems of hydrodynamics and continuum theory as past of elasticity theory. Solutions, based exclusively on statistic interpretation of experiment results and on correlation correspondences, underlie the second group. Semi-empirical methods include those in which hydraulic destruction is based on correction of equations for relationship between hydraulic jets' parameters and several characteristics of rock (usually strength limit and hardness), which were accepted a priori (or taken from 
previous researches), with the help of empirical coefficients.

While working on theory to describe hydraulic destruction of rocks by means of high speed water jets, as well as when using semi- empirical equations, calculation methods are based on solving two particular problems: determination of jet pressure on the contact surface (barrier) and determination of stress components in solid body.

Works (Garbuz, 1975; Nikonov et al, 1986; Pykhteev, 1996) suggest a solution, based on boundary problems, which covers all known flat jet steady flows of incompressible non-vicious fluid when Zhukovsky's function is introduced into the calculation method. We can have a flat model because mappings of complex potential range $\mathrm{w}=\phi+i \varphi$ of ax symmetric flow are quasi-conformal and have basic properties of conformal mappings, which are particularly oriented on solving plane problems. As a result the problem resolves into finding velocity and pressure fields in the jet with infinite discharge - consumption $Q$ and velocity $v_{0}$, flowing over the unbounded elastic body of given form and spreading at the boundary $L$ of this body (Figure 1). The main sought quantity is the distribution of pressure at the boundary $L$ as the function of curved abscissa $S$ for line $L$. It is sufficient to find complex potential of the velocity at each point $z=x+i y$ of the flow range. Under this approach the complex potential range, which is a cut line, is mapped on the upper semi-plane with corresponding points, marked on Figure 1.
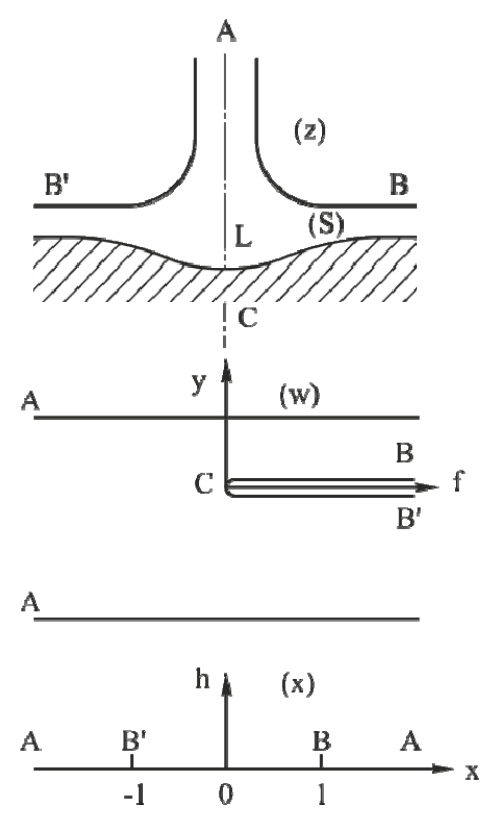

Pic. 1. Scheme of interaction between jet and elastic body, complex potential $w$ and canonical domain $\zeta$ with vertical axis $\eta$

As a result we get the following general formula for jet pressure $P$ with regard to its distribution at $L$ :

$$
P-P_{0}=\frac{\rho v_{0}^{2}}{2}\left\{1-\exp \left[2\left(I(U / \xi)+2 \sigma \ln \frac{\xi}{1-\sqrt{1-\xi^{2}}}\right)\right]\right\}, \quad \xi \in[-1,1]
$$

where $P_{0}$ - pressure on stress-free boundary of the jet; $\rho$ - specific gravity of the fluid; $I(U / \xi)=-I_{m} F(\xi)$ according to the integral representation of Zhukovsky's function $\left(I_{m}\right.$ - imaginary component of functions with complex variable, $F(\xi)$ - Zhukovsky's function); $\sigma$ - tangent angle угол наклона касательной to the boundary $L$.

Apart from the given formula, there are functional equations of curved abscissa $S$ and grid coordinates $x(\xi)$ 
and $y(\xi)$. Finding the distribution of pressure at the boundary of a solid body consists in determination of real auxiliary function $U(\xi)$, which is the solution for the boundary problem.

As already mentioned, the next problem is to specify the quantitative pattern of rock's stress condition, caused by contact pressure of jet. These works suggest using Kolosov-Muskhelishvili formulas to calculate components of axis stress:

$$
\begin{aligned}
& \sigma_{x}+\sigma_{y}=4 \operatorname{Re} \Phi(z) \\
& \sigma_{y}-\sigma_{x}+2 i \tau_{x y}=2[\bar{z} \Phi(z)+\Psi(z)],
\end{aligned}
$$

where $\Phi(z), \Psi(z)$ - analytical functions of stress and boundary conditions for elastic bodies with boundary $L$, filling the semi-space,

$$
\tau_{\chi \gamma}(S)=0, \quad \sigma \quad(S)=-\left(P-P_{0}\right) .
$$

Analytical functions should satisfy the following condition:

$$
2 \operatorname{Re} \Phi(S)+\bar{z} \Phi^{\prime} /(S)+\Psi(S)=-P(S), S \in L
$$

where $P(S)$ - hydrodynamic pressure at $L$, calculated according to the formula (1).

Therefore, the problem of finding stresses resolves into finding in range $S$ the functions $\Phi(z)$ and $\Psi(z)$, diminishing at the infinity according to the boundary condition (4). Following the results of calculation, the paths of principal $\sigma_{x}$ and $\sigma_{y}$ and maximum tangents $\tau_{x y}$ of stresses are plotted (Figure 2).
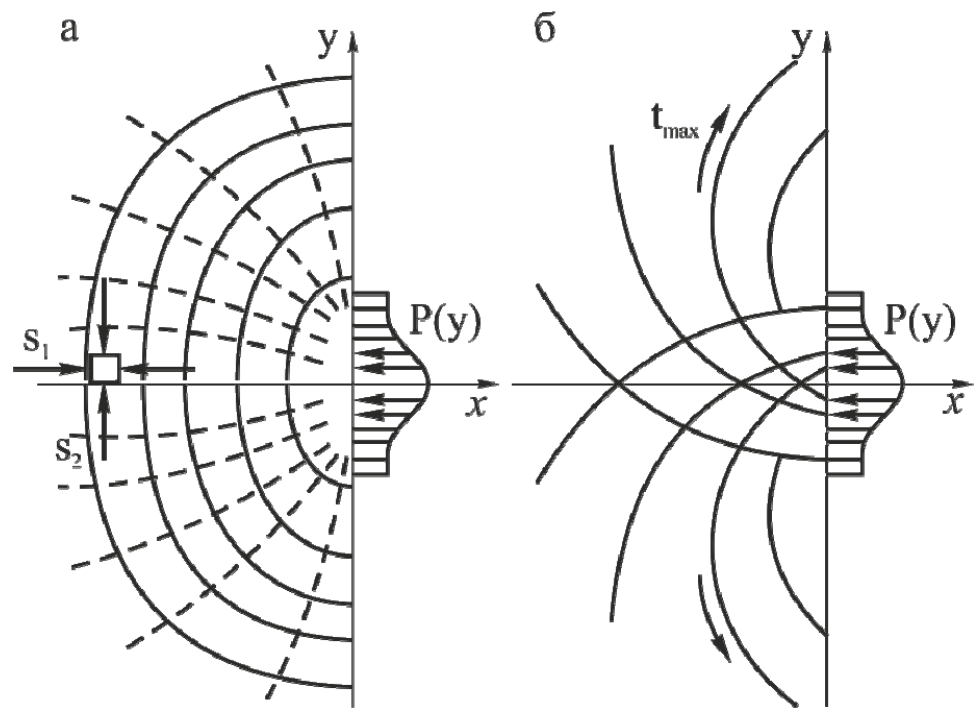

Figure 2. Distribution of principal (a) and tangent (б) stresses in solid body under water jet exposure

However, this model is not oriented on any particular body - rock under destruction, because it does not have any properties of this rock (e.g. elasticity modulus, Poissont's ratio, strength limit or hardness, adhesion, angle of internal friction, etc.). As a result, we can only get a qualitative image of stress field, maintaining general rules of its distribution in the body.

Authors of works (Garbuz, 1975; Nikonov et al, 1986; Pykhteev, 1996) do not dwell upon method of further research. Calculation results are supposed to be a comparison between the obtained stresses and critical (in the sense of destruction) properties of the body, being exposed to water jet. For example, such comparison can be carried out, basing on general condition of hardness (Shavlovsky, 1979): 


$$
\left(\sigma_{x}-\sigma_{y}\right)^{2}+4 \tau_{x y}^{2}=\left(\sigma_{x}+\sigma_{y}+2 C \cos \phi\right)^{2} \sin ^{2} \phi
$$

where $C$ and $\varphi$-adhesion and angle on internal friction of the solid body (rock).

Besides, with the help of the suggested method it is possible to solve only a part of the problems, connected with frontal onset of water jet on the barrier with different configuration (that is an advantage of the conformal mapping of solid body with curved surface on linear semi-plane). This method is also not oriented on describing rock destruction by means of submerged jets.

One of the most common approaches to the solution of the first part of the general problem of hydraulic destruction of rocks is using the theory quantity of motion in $\mathrm{X}$-direction force (Figure 3 ).

In general case equations of momentum conservation for this problem with projection on $X$ and $Y$ have the following form:

$$
\begin{aligned}
& m_{1} v_{1} \cos \alpha_{2}-m_{2} v_{2} \cos \alpha_{2}-m v=-\Delta t R \sin \alpha_{2} \\
& m_{1} v_{1} \sin \alpha_{2}-m_{2} v_{2} \sin \alpha_{2}-0=\Delta t R \cos \alpha_{2},
\end{aligned}
$$

where $m_{1}, m_{2}$ and $m$ - discharge rate of fluid mass in the corresponding cross-sections (see Figure 3); $v_{1}$, $v_{2}$ and $v$ - jet velocity in the same cross-sections; $\alpha_{2}$ - barrier's slope angle with reverse flow of fluid; $R$ -barrier's response; $\Delta t$ - time period of impulse force of jet applied to the barrier.
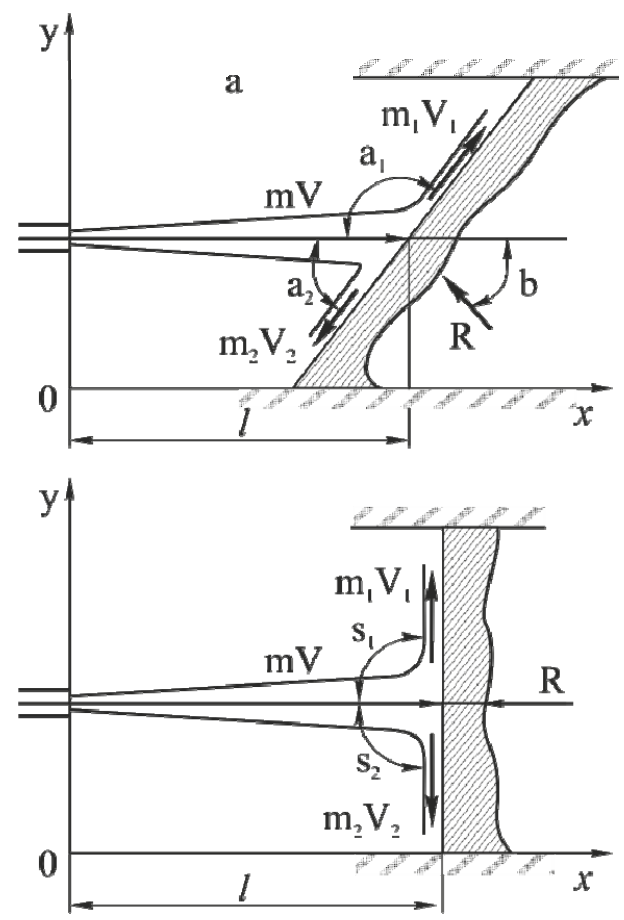

Figure 3. Jet effect on barrier mass, placed at an angle to the jet direction and at the right angle

With both formulae (6) combined we get the following equation for calculation of barrier's response (Shavlovsky, 1979) :

$$
R=F_{n} \frac{\gamma}{g} v_{a v}^{2} \sin \alpha_{2}=F_{n} \rho_{a v} v_{a v}^{2} \sin \alpha_{2}
$$

where $P=F_{n} \rho_{a v} v_{a v}^{2}$ - force of the jet; $v_{a v}$ - average velocity of the jet with distance $l$ from the pipe to the barrier; $\gamma$ - specific gravity of the aerated fluid of the jet at distance $l$ from the pipe; $g$ - free fall acceleration; $\rho_{c p}$ - average density of the aerated fluid of the jet at distance $l$ from the pipe; $F_{n}$ - full area of cross-section of the jet at distance $l$ from the pipe. 
Final form of the jet impact force applied to the flat barrier can be found with the formula (Shavlovsky, 1979):

$$
\mathrm{P}=\frac{\pi \mathrm{d}_{0}^{2}}{4} \frac{\mu}{\mathrm{K}_{0}} \sqrt{\mathrm{p}_{0} / \mathrm{p}_{\mathrm{av}}} \rho_{\mathrm{av}} \mathrm{v}_{\mathrm{av}}^{2} \sin \alpha
$$

where $\mu$ - coefficient of pipe discharge; $p_{0}$ - initial jet pressure; $p_{a v}$ - average dynamic jet pressure at distance $l$ from the pipe; $d_{0}$ - initial diameter of the jet; $K_{0}$ - coefficient of jet aeration degree; $\alpha$ - barrier's slope angle.

To calculate jet force at the moment of kerf formation the equation (8) is transformed into:

$$
\mathrm{P}=1,5 \frac{\pi \mathrm{d}_{0}^{2}}{4} \frac{\mu}{\mathrm{K}_{0}} \sqrt{\mathrm{p}_{0} / \mathrm{p}_{\mathrm{av}}} \rho_{\mathrm{av}} \mathrm{V}_{\mathrm{av}}^{2}
$$

Equations (8) and (9) are used, basing on the experimental approval of hydrodynamic properties of jets (such as $\left.\mu, p_{a v}, K_{0}\right)_{\text {of }}$ different initial pressure and diameter of the pipe. However, jets for water jet grouting of unstable rocks have another set of quantitative (Shavlovsky, 1979): parameters, making impossible the use of existing calculation formulae to find their basic properties. The work (Nurok, 1979) in order to calculate jet impact force suggests using the formula, obtained from the combined solution of impulse equation and the equation for fluid's flow continuity:

$$
\mathrm{P}=\mathrm{p}_{0}\left(1-\frac{1}{100 \frac{\rho_{\mathrm{m}}}{\rho}\left(\frac{\mathrm{v}_{\text {jet }}}{\mathrm{v}_{\mathrm{o}}}\right)^{2}}\right)
$$

where $\rho_{m}$ and $\rho$-density of water and density of the jet correspondingly on the axis; $v_{j e t}$ and $v_{0}$-axis velocity of the jet and velocity of jet outflow from the pipe.

This equation from the theoretical point of view is relatively more universal, as it uses only the properties of particular equipment being used. Certain problems arise when we calculate the velocity $v_{j e t}$. Professor G. N. Abramovich (Abramovich, 1960) in order to find it suggested using an equation, enabling to solve the problem of finding force impact exactly for the submerged axisymmetrical jet:

$$
\mathrm{v}_{\text {jet }}=\frac{0,96}{0,16 \frac{1}{\mathrm{~d}_{0}}+0,29} \mathrm{v}_{0} .
$$

He also gives formulae to calculate velocity in any point of the jet, diameter of the jet $d$ and spreading angle $\alpha$ :

$$
v=v_{c m p} e^{-\frac{1}{2}\left(\frac{r}{0,08 l}\right)^{2}}, \mathrm{~m} / \mathrm{s}
$$

where $r$ - normal distance from jet axis to the given point, $\mathrm{m}$.

$$
\begin{gathered}
\mathrm{d}=\left(0,27 \frac{1}{\mathrm{~d}_{0}}+1\right) \mathrm{d}_{0}, \mathrm{~m} \\
\alpha^{\prime}=1+\frac{31,25 \mathrm{~d}_{0}^{2}\left(\frac{1,141}{\mathrm{~d}_{0}}+1\right)^{2}-7,81 \mathrm{~d}_{0}^{2}}{1^{2}} .
\end{gathered}
$$

Having inserted (11) into (10), we get: 


$$
P=p_{0}\left(1-0,01 \frac{\rho}{\rho_{m}}\left(\frac{0,16 \frac{l}{d_{0}}+0,29}{0,96}\right)^{2}\right)
$$

or, with regard for the area of contact spot of the jet and rock mass:

$$
F=\frac{\pi d_{0}^{2}}{2}\left(1-\frac{1}{100 \frac{\rho}{\rho}\left(\frac{v_{j e t}}{v_{0}}\right)^{2}}\right) .
$$

The obtained equation, due to the fact that it contains only the initial hydrodynamic properties of jets, can be easily applied to mine technical conditions of water jet grouting of unstable rocks and to the equipment being used.

To estimate hydraulic destruction of rocks, the work (Nurok, 1979) suggested a method, based on the following conditions:

rock under destruction is homogeneous and isotropic;

destruction of the rock starts right after the shearing stress goes beyond elasticity limit;

jet load impacts statically, is applied to a circle area and has circular symmetry;

surface under load is a plane;

load is distributed on the circle area according to the parabolic law for any cross-section of the jet (Figure 4);

Position of the point of the rock under destruction is characterized by cylinder coordinates $r$ and $v$ (in circle's plane), and also $Z$ (axis $O Z$ goes through the center of the circle).

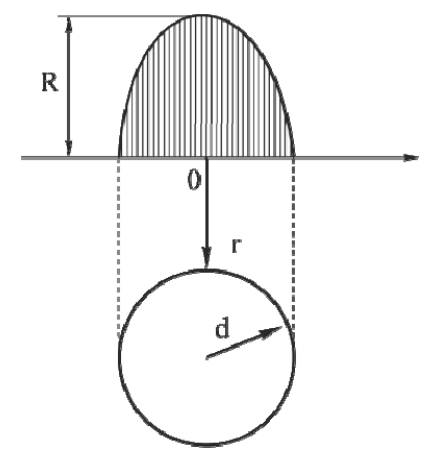

Figure 4. Scheme of load distribution on the barrier, exposed to the jet

Then components of the stress tensor $\left|\begin{array}{c}\sigma_{r} \tau_{r v} \tau_{r z} \\ \tau_{r v} \sigma_{v} \tau_{z v} \\ \tau_{r z} \tau_{z v} \sigma_{z}\end{array}\right|$ can be formulated for equal loading when using the solution for Boussinesq problem (Tsytovich \& Martirosyan, 1981) with the following equations: 


$$
\begin{gathered}
\sigma_{r}=\sigma_{v}=p_{0}\left[(1-2 v) I_{1}^{\prime}+2(1+v) I_{2}^{\prime}-I_{3}^{\prime}+2(2-v) I_{4}^{\prime}-I_{5}^{\prime}-\frac{1}{2}(1+2 v)\right] \\
\sigma_{z}=p_{0}\left(2 I_{3}-1\right) ; \tau_{r v}=\tau_{z v}=0 ; \tau_{r z}=-p_{0} I_{0},
\end{gathered}
$$

where $v$ - Poisson's ratio; $\mathrm{I}_{0}^{\prime}-\mathrm{I}_{5}^{\prime}$ - integrals, numerically calculated for different values $z / a$ and $r / a ; a-$ circle's radius under load.

Maximum tangent load that causes the destruction of brittle rocks is calculated according to the formula:

$$
\tau_{\max }=\sqrt{\left(\frac{\sigma_{r}-\sigma_{z}}{2}\right)^{2}+\tau_{r z}^{2}} .
$$

After some manipulations the following formula is suggested to be used to calculate the ultimate force of jet impact on rock:

$$
P=\frac{2 \tau_{c}}{\frac{1-2 v}{2}+\frac{2}{9}(1+v) \sqrt{2(1+v)}},
$$

where $\tau_{c}-$ ultimate shearing stress of the rock under destruction.

Therefore, combining solutions for equations (15) and (18) we can calculated the depth of jet penetration into the rock mass, knowing rock's properties included into equation (18). In this equation the ultimate shearing stress is a criterion for destruction, and the rock itself is characterized only by Poissont's ratio. If the rock is unstable or weakly stable (these are clays and clayish soil mostly), during the water jet grouting works we have to look up not to elasticity of the mass, but to its plastic properties, which are known in rock mechanics as the strength condition (Bulychev, 1994; Rzhevsky et al., 1984).

In this case rocks are characterized by adhesion, angle of inner friction and strength limit. Use of this method is not quite reasonable because loosely bound rocks are destructed along the formed area element of sliding surface and not along the shearing areas, which have a bigger angle.

In assertion of parameters of jet destruction of rocks empirical formulae, which can be divided into two groups, play the main role. The first group is formed of equations, obtained from the experiments - by means of statistic processing of research results. The second group is based upon already known equations, but with new empirical coefficients, calculated for the given mine technical situation.

Thus, for example, in A.A. Skochinsky Institute of Mining the following correspondences between jet and destruction properties were obtained (Kuzmich et al, 1972):

$$
\begin{aligned}
& \bar{h}\left(p_{0}\right)=C\left(p_{0}-\bar{p}_{c r}\right) ; p_{0} \geq \bar{p}_{c r} ; \\
& \bar{h}\left(v_{n}\right)=h_{0} \exp \left(-\alpha v_{n}\right) ; \\
& \bar{h}\left(d_{0}\right)=B d_{0}^{n} ; 1 \leq n \leq 1,5 ; \\
& \bar{h}(k)=A k^{\beta},
\end{aligned}
$$

where $\bar{h}$ - gap depth; $p_{0}$ - jet pressure; $\bar{p}_{c r}$ - critical pressure, at which the destruction starts; $h_{0}$ - depth of destruction with fixed jet; $d_{0}$ - pipe diameter; $k$-resistance to hydraulic destruction; $A, B, C, \alpha, \beta, n$-empirical coefficients, obtained from experiments results. Equations (19) should be oriented on brittle rocks with hardness of coal and harder.

Method introduced in work (Shavlovsky, 1979): also deserves attention. It is based on functional equation in dimensionless form: 


$$
\frac{h_{p}}{D_{B}}=f\left[\frac{l}{d_{0}} ; \frac{\sigma_{c}}{p_{m}} ; \frac{D}{\psi_{0} p_{a v} t}\right],
$$

where $h_{p}$ - depth of the formed destruction pit; $D_{b}$ - pit diameter; $p_{m}$-dynamic axle pressure of the jet at the place of contact with the mass; $\sigma_{c}$ - breaking strength of rock under simple compression; $l$ - distance from the pipe to the given jet cross section; $D$ - jet diameter at the point of contact with rock mass; $p_{a v}$ - average dynamic jet pressure; $\psi_{0}$ - specific water absorption of coal layer; $t$ - time of jet exposure on rock.

For each of the relative properties of formula (20) exponential function and its influence on $\frac{h_{p}}{D_{b}}$ is set by means of experiment. This equation, as well as the group of equations (19), is oriented on brittle rock with one initial property - strength limit under compression.

Thus, the analysis shows, that in order to built interrelations between the properties of hydraulic destruction of loosely bound and/or unstable rocks during water jet grouting, other criteria of rock's breaking strength, based as was mentioned above on plasticity (strength) theory, should be used. At the same time, equation (15) can be used to find external force applied to the mass (jet impact force) with high accuracy.

For qualitative evaluation of jet grouting, the work (Broid, 2004) suggests to regard abrasive destruction as the main factor of jet destruction of rock mass. It is quite difficult to characterize all processes taking place in this case, so the author states the approaches to the estimation of jet grouting efficiency, basing on the analysis of real-life experience in this field. Thus, for construction of cement-bound columns according to two component technology, based on field experimental research (Fedorov \& Petrosyan, 1983) and analytical methods, the author obtained calculation correspondence for finding the radius of cement-bound column $R_{u}$.

$$
R_{u}=337 \frac{\left(d_{g}+D_{a}-D_{g}\right)^{0,25}}{\operatorname{Re}_{g a}^{0,5}}\left(\frac{0,05 \rho_{g a} g E_{0}}{\pi n I_{s} v_{y}}\right)^{0,75}
$$

where $d_{g}$ - diameter of jetting pipe; $D_{a}$ - inner diameter of pumping air pipe; $\mathrm{Re}_{g a}^{0,5}-$ Reynolds number for the jet in co-current air flow; $\rho_{g a}$ - average density of matrix jet in air flow; $E_{0}$ - specific kinetic energy in the initial cross-section of the jet; $n$ - porosity of loose soil; $I_{s}$ - properties of soil under jetting; $v_{y}$ - monitor lift speed.

Values of $E_{0}, \rho_{g a}, \mathrm{Re}_{g a}^{0,5}$ are calculated according to the same formulae used for water jet in co-current airflow with the following parameters: pipe diameter, velocity and density of matrix jet. Calculation of $\mathrm{Re}_{g a}^{0,5}$ is carried out, basing on the density of matrix and dynamic viscosity of water.

The author believes that the correspondence (21) is effective, that is that it can be used for preliminary project calculations. When additional experimental data are gathered, the values of constants can be specified. However, it cannot be used for one component technology, which is more common and economically sound.

Despite the fact that one component jetting of soil during its stabilization is easier in comparison to the jetting of soil in co-current airflow, it is difficult to find rules of such jetting type.

Then, considering that the processes taking place during jet grouting under all; known technologies are the same, the author suggests the following general formula by analogy with (21):

$$
R_{u}=K_{1} \frac{\left(d_{g}+D_{a}-D_{g}\right)^{a}}{\operatorname{Re}_{g a}^{b}}\left(\frac{30 \rho_{w a} g E_{0}}{\pi n I_{s}}\right)^{c} \frac{0,00826}{v_{y}^{0,75}}
$$

Where values of constants $a, b, c$ can be calculated, basing on approximation of correspondences, suggested by different authors or on practical results of completed works.

Basing on the analysis and results of experimental works, there are specific values of constants in the following formula (22) for technological parameters used in Russian jet grouting:

$$
R_{u}=1052,5 \frac{d_{g}^{0,5}}{\operatorname{Re}_{g a}^{0,5}}\left(\frac{30 \rho_{w a} g E_{0}}{\pi n I_{s}}\right)^{0,25} \frac{0,00826}{v_{y}^{0,75}}
$$


However, this approach is not based on knowledge of interaction between water jet and rock mass during jet grouting and is formal. Each particular case of implementation needs to be checked and specified.

\subsubsection{Development of Calculation Method for Rock's Jet Grouting Process Properties}

As mentioned above, the process of rock mass destruction during the jet grouting is characterized by shearing of the rock mass due to dynamic pressure of the jet. While considering the process discretely we can assume that the destruction takes place within elementary volume with two curved surfaces, which are formed along the shearing area as dynamic impact of hydraulic monitor is decreased gradually. In plane interpretation - on cross section at the operational depth of the borehole - this volume with one surface is depicted on Figure 5.

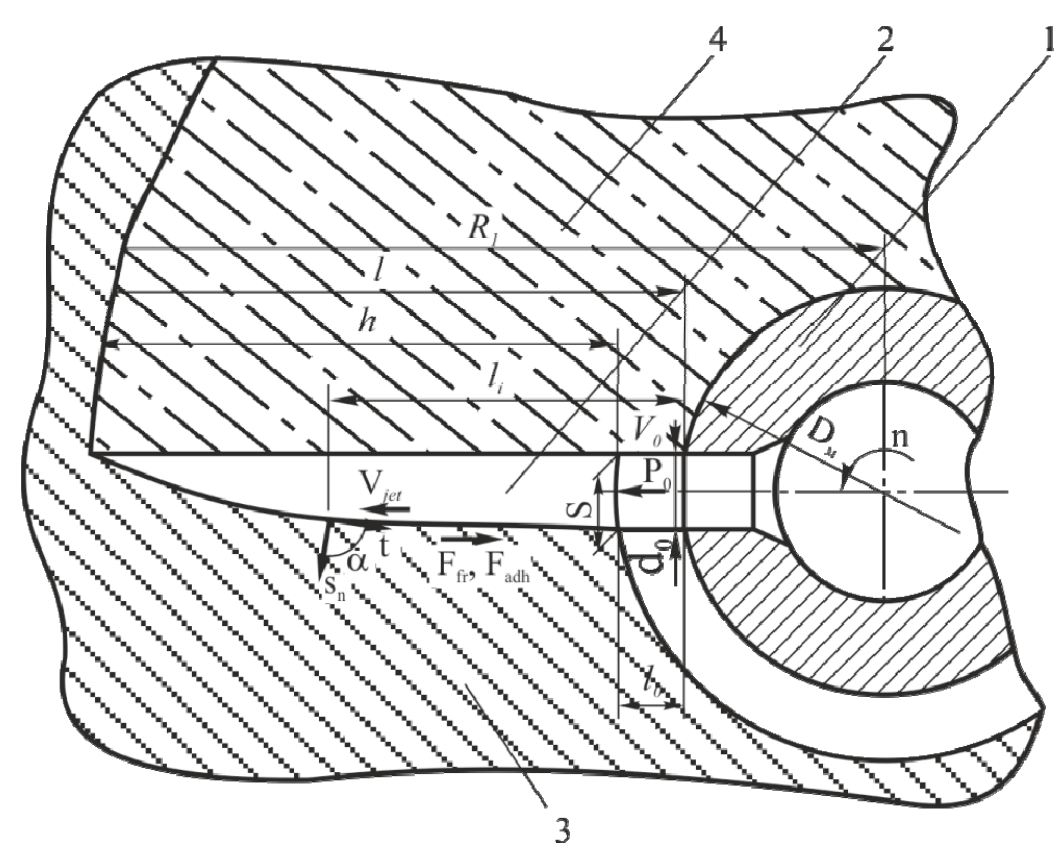

Figure 5. Calculation scheme of interaction between water-cement suspension jet and the rock mass: 1 - rod; 2 water-cement jet; 3 - initial rock mass; 4 - strengthened rock mass; $R_{l}$ - radius of rock mass being cemented, $\mathrm{m}$; $l_{0}$ - distance between jet-forming pipe and the surface of the rock, $\mathrm{m} ; h$ - depth of rock's destruction, $\mathrm{m} ; S$ - area of contact between jet and rock mass, $\mathrm{m}^{2} ; D_{M}$ - monitor's diameter, $\mathrm{m} ; \alpha$ - slope angle of curved surface towards jet direction

The main characteristics of such volume are: $h$ - depth of rock's destruction; $\alpha$ - slope angle of curved surface towards jet direction (slope angle of sliding and shearing areas).

To characterize plastic properties (hardness) of the rocks the plastic model is used - Mohr-Coulomb theory, that includes the following rules:

plastic deformations (destruction) take place due to the shift along the sliding areas;

adhesion and friction prevent shearing along the sliding areas;

plasticity (hardness) of a rock is determined by the values of maximum and minimal stresses; in case of simple compression - only by the value of maximum compression stresses.

Mohr-Coulomb plasticity (hardness) condition is the fundamental equation in this theory:

$$
\frac{F}{S}=\tau=C+\sigma_{n} \operatorname{tg} \phi
$$

where $F=F_{a d h}+F_{f r}$ - jet impact force, $N$; $S$ - area of contact between the jet and the rock, $\mathrm{m}^{2} ; C$ - adhesion coefficient, $\mathrm{MPa} ; \varphi$ - inner friction; $\tau$ - stress tangents, MPa; $\sigma_{n}-$ stress normals, MPa.

Condition (24) is also called limit state condition. Graphically equation (24) is the strength certificate (Figure 6) - it is an envelope of the maximum circles of stress, applied to the rock at the strength limit. On Figure $6, \varphi$ is a tangent to stress circle. 
From the strength certificate it is possible to get the following equations:

$$
\begin{aligned}
& \sigma_{n}=\frac{1}{2} \sigma_{c}(1-\sin \phi) ; \\
& \tau_{c}=\frac{1}{2} \sigma_{c} \cos \phi
\end{aligned}
$$

or

$$
\begin{aligned}
& \sigma_{n}=\sigma_{c} \sin ^{2} \alpha \\
& \tau_{c}=\frac{1}{2} \sigma_{c} \sin 2 \alpha .
\end{aligned}
$$

a

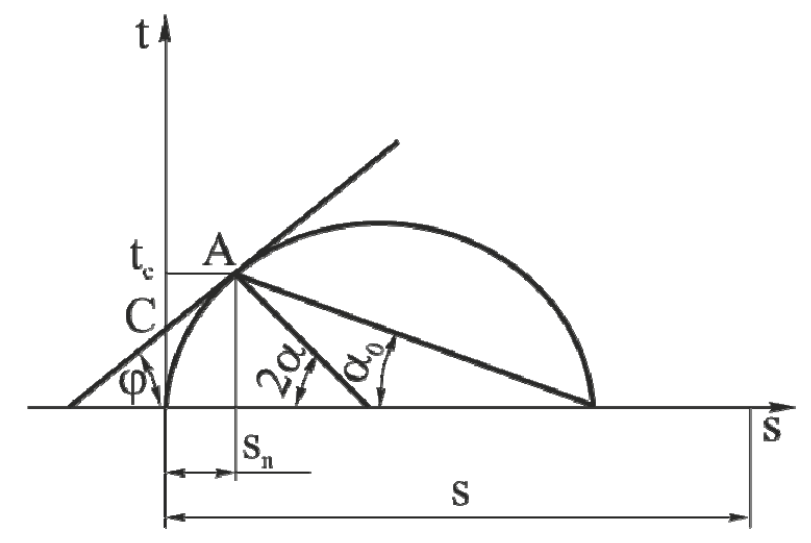

$b$

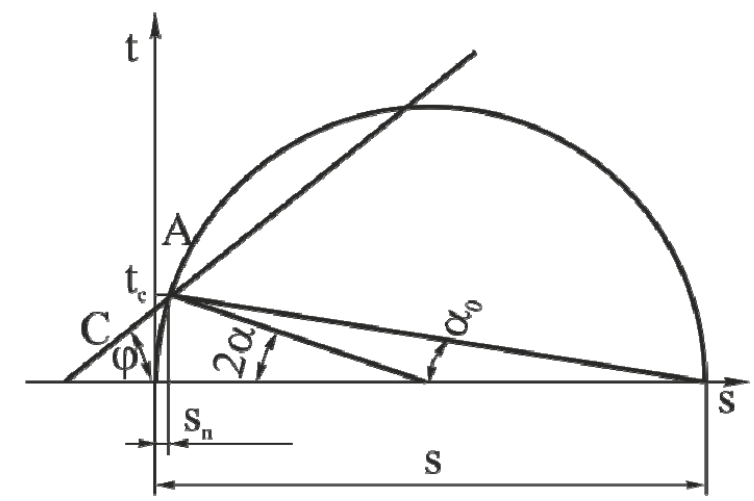

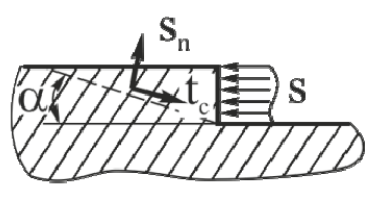

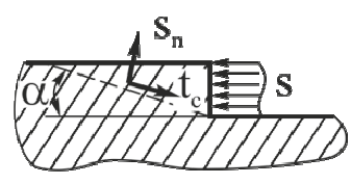

Figure 6. The strength certificate and arrangement of sliding areas with respect to the maximum stresses (a) equaling strength limit and (b) exceeding it

In equations (25) and (26) $\sigma_{c}$ is the strength limit for simple compression. Then plasticity condition (24) can be formulated as follows:

$$
\frac{1}{2} \sigma_{C} \cos \phi=C+\frac{1}{2} \sigma_{C}(1-\sin \phi) \operatorname{tg} \phi
$$

or

$$
\frac{1}{2} \sigma_{c} \sin 2 \alpha=C+\sigma_{c} \sin ^{2} \alpha \operatorname{tg} \phi
$$

After some simple transformations, we get: 


$$
\sigma_{c}=\frac{2 C \cos \phi}{1-\sin \phi}
$$

or

$$
\sigma_{c}=\frac{2 C}{\sin 2 \alpha-2 \sin ^{2} \alpha \operatorname{tg} \phi}
$$

If the equation (29) characterizes the connection between the strength limit, adhesion and inner friction angle, then equation (30) also reflects slope angle of the sliding area, along which the destruction of rock is directed (see pic. 6). When passing to stress condition of destruction's elementary volume, equation (30) still keeps its physical matter; instead of strength limit, the maximum stress, appearing from the applied load of the jet, should be inserted into it. Then:

$$
\sigma_{\max }=\frac{2 C}{\sin 2 \alpha-2 \sin ^{2} \alpha \operatorname{tg} \phi}
$$

The most important sought property in this equation is the slope angle of tangent to the curved surface of the destructed elementary volume of the rock. After some trigonometric transformations, equation (31) is reduced to the following form:

$$
\left(\frac{C}{\sigma_{\max }}+\operatorname{tg} \phi\right) \operatorname{tg}^{2} \alpha-\operatorname{tg} \alpha+\frac{C}{\sigma_{\max }}=0
$$

In fact, this equation is quadratic and as a result, its solution can be written in the following form:

$$
\alpha=\operatorname{arctg}\left(\frac{\left.1-\sqrt{1-4 \frac{C}{\sigma_{\max }}\left(\frac{C}{\sigma_{\max }}+\operatorname{tg} \phi\right.}\right)}{2\left(\frac{C}{\sigma_{\max }}+\operatorname{tg} \phi\right)}\right)
$$

Effectiveness of this formula can be analyzed in real example of destruction, for example, of thin-layer bluestone, with adhesion coefficient equaling $0,02 \mathrm{MPa}$, and inner friction angle of $25^{\circ}$ (Bulychev,1994) . Using equation (1.299), we find strength limit for simple compression: $\sigma_{c}=0,063 \mathrm{MPa}$. With such properties of the clay (when it is at the strength limit point) slope angle of the sliding area will be $32,5^{\circ}$. Twofold increase of the stress decreases the slope angle of the area to $10,2^{\circ}$, fivefold increase - to $3,8^{\circ}$, tenfold - to $1,9^{\circ}$. This calculation example adequately covers the physical matter of hydrodynamic pressure of water on the rock, as, in fact, increasing the distance from jet-forming pipe, the slope angle (due to the decrease of pressure, and therefore of stresses in the cross sections of the elementary volume along its length) gradually grows, reaching at the end the maximum value, if $\sigma_{\max }=\sigma_{c}$.

Note that the severance of the elementary volume of the rock goes along two mutually perpendicular curved surfaces (that is the sliding areas). Due to this fact the pressure, formed along the whole length of the jet should satisfy the following relation:

$$
P_{l} \geq 2 \sigma_{\max }
$$

Basing on this relation, the slope angle of the sliding area at any distance from the pipe and with known pressure will be calculated according to the formula: 


$$
\alpha=\operatorname{arctg}\left(\frac{\left.1-\sqrt{1-16 \frac{C}{P_{l}}\left(\frac{C}{P_{l}}+\frac{1}{2} \operatorname{tg} \phi\right.}\right)}{4\left(\frac{C}{P_{l}}+\frac{1}{2} \operatorname{tg} \phi\right)}\right)
$$

Basing on the equation (15), condition for rock destruction can be formulated as follows:

$$
\frac{p_{0}}{2}\left(1-0,01 \frac{\rho}{\rho_{m}}\left(\frac{0,16 \frac{l}{d_{0}}+0,29}{0,96}\right)^{2}\right) \geq \sigma_{c}
$$

or, basing on formula (29)

$$
\frac{p_{0}}{4}\left(1-0,01 \frac{\rho}{\rho_{m}}\left(\frac{0,16 \frac{l}{d_{0}}+0,29}{0,96}\right)^{2}\right) \frac{1-\sin \phi}{\cos \phi} \geq C
$$

If the slope angle of the sliding area is taken into account, basing on (30) the destruction condition will be as follows:

$$
\frac{p_{o}}{4}\left(1-0,01 \frac{\rho}{\rho_{m}}\left(\frac{0,16 \frac{l}{d_{0}}+0,29}{0,96}\right)^{2}\right)\left(\sin 2 \alpha-2 \sin ^{2} \alpha \operatorname{tg} \phi\right) \geq C
$$

Or, taking into account (25), the following relation will be the destruction condition:

$$
P \frac{\pi d^{2}}{2 S}\left(1-\frac{1}{100 \frac{\rho_{m}}{\rho}\left(\frac{v_{c m p}}{v_{0}}\right)^{2}}\right)(\cos \alpha-\sin \alpha \cdot \operatorname{tg} \phi) \geq C
$$

Combined solution of relations (11), (13) and (39) with regard to relation (14) or (35) allows calculating the form and the volume of the destructed layer of rock mass and helps estimating the effectiveness of water jet impact during water jet grouting of rocks. 


$$
\left\{\begin{array}{l}
v_{j e t}=\frac{0,96}{\frac{0,16 l}{d_{0}}+0,29} v_{0} \\
d=\left(0,27 \frac{l}{d_{0}}+1\right) d_{0} \\
P \frac{\pi d^{2}}{2 S}\left(\begin{array}{l}
\left.1-\frac{1}{100 \frac{\rho_{m}}{\rho}\left(\frac{v_{c m p}}{v_{0}}\right)^{2}}\right)(\cos \alpha-\sin \alpha \cdot \operatorname{tg} \phi)-C=0 .
\end{array}\right) .
\end{array}\right.
$$

Solution for the combined equations (40) with respect to $l$ allows calculation the depth of penetration of the water-cement suspension jet into the rock mass. Thus the diameter of the strengthened rock mass $D=2 R_{l}=2 l+$ $D_{M}, \mathrm{~m}$, is found.

\section{Results}

Waterjet cementation method is based on implementation of kinetic energy of high-pressure concrete jet that destructs and at the same time mixes the rock with mortar. After the hardening of mortar a new material, called soil-concrete, is created. Soil-concrete has rather high hardness and deformation parameters.

Waterjet cementation can be used in different types of rocks, including all types of subsoil -from gravel detritus to fine clays and clayed silt. Due to these characteristics waterjet cementation technology is better than any traditional methods of injection reinforcement of subsoil.

The list of practical ways to implement waterjet cementation is more than impressive now. It is used as an effective means of restraint of weak rocks during tunnels and collectors construction; also it is used for the construction of excavation pit fences in flooded rocks, and for ground water cutoffs, in order to improve hardness of the foundation during the reconstruction and construction of buildings. Only this unique method allows restraint of rocks at the core of the foundation slab and of unstable slopes and bevel edges, and helps to eliminate caverns in fractured hard rocks.

Traditionally works with the use of waterjet cementation come down to the use of special drilling machines, drilling a well down to the needed depth, with further high-pressure water-cement feeding through pivoting drilling column perpendicularly to the axis of the drilled well and with raising of the drilling instrument to the design level. This way a cylindrical body, consisting of fine compo of water concrete matrix and rock, is formed in the rock mass. Sometime later, the compo sets and fastens, creating a column, made of a new material concrete rock.

There are works concerning the creation of flat concrete rock constructions in rock masses by means of repeated reciprocating moving without the rotation of jet-forming instrument along the preliminarily drilled pilot bore.

First experimental works introducing waterjet technology into Russian practice were carried out by the institutions "Gidrospetsproekt" and Scientific and Research Institute of Beddings and Subterranean structures named after M.N. Gersevanov back in 1979-83Г ( Brenner et al, 2007). The jet technology was used for the first time in the industry for construction of vertical ground water cutoffs, excavation of frozen soil for a pit, and also for hardening of collapsing soil by means of soaking (Ukhov et al , 2002; Pettit,1988; Golovin et al, 2008; Korolev et al,2006)

This technical solution let us suggest that the waterjet cementation method will also be highly effective for creation of flat extended concrete rock construction (for example, for road construction).

\section{Discussion}

That is why it is no coincidence that scientists and specialist from Tula State University carried out a research, 
aimed at finding major laws of getting restrained concrete rock constructions without dipping the jet-forming instrument into the rock mass.

Basically, waterjet cementation of road surface can be carried out with jet-forming device, being placed directly at the subsoil surface or at some distance from the surface. The first scheme is more preferable from the point of view of raising effectiveness of exposure on the restrained rock mass and reducing water concrete matrix loss at spraying when the jet enters the subsoil, that is why it was decided to discuss this case ( Kovalev \& Afonsky, 2013; Sližytė \& Medzvieckas 2013; Malinin \& Gladkov , 2011).

The process of waterjet cementation (Figure7) goes the following way: jet-forming instrument (diameter is $d_{0}$, discharge coefficient is $\mu$ ) is fed with water concrete matrix (density is $\rho$ ) under high pressure $P$. After that the jet-forming instrument is moved at the speed $V$ along the surface of the rock mass being fastened.

After the hardening a fastened mass with a triangular cut, depth $h$ and point angle $\gamma$ is formed.

All the listed factors of waterjet cementation process can be divided into the following groups:

- constructional: coefficient of water concrete suspension discharge through the jet-forming pipe $\mu$, diameter of the jet-forming pipe hole $d_{0}$;

- performative: density of water concrete suspension $\rho$, speed of instrument movement $V$, pressure of water concrete suspension $P$;

- physical and mechanical parameters of rocks (basing on the analysis of literature data, rock adhesion coefficient $C$ was chosen as a criterion for subsoil resistance to the water jet exposure).

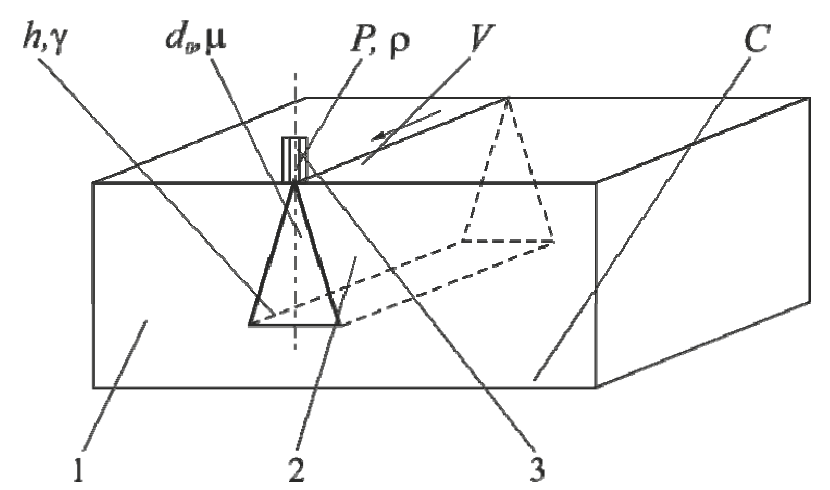

Figure 7. Scheme of waterjet cementation of road surface: 1 - surface being fastened; 2 - concrete rock; 3 jet-forming pipe

The following parameters were chosen the major criteria of waterjet cementation effectiveness: depth of fastening $h$, speed of rock mass volume expansion $G_{0}$ (performance) and storage density of waterjet cementation of rocks $E_{0}$.

Speed of rock mass volume expansion $G_{0}\left(\mathrm{~m}^{3} / \mathrm{s}\right)$ was estimated as multiplication of speed of instrument movement and area of the mass being fastened according to the formula:

$$
G_{0}=V h^{2} \operatorname{tg} \frac{\gamma}{2}
$$

where $h$ - cementation depth, $\mathrm{m} ; \gamma$ - point angle of the mass being fastened, deg; $V$ - speed of instrument movement, $\mathrm{m} / \mathrm{s}$.

Storage density of waterjet cementation of rocks $E_{0}\left(\mathrm{MJ} / \mathrm{m}^{3}\right)$ is estimated according to the formula:

$$
E_{0}=\frac{N}{G_{0}}
$$


where $\mathrm{N}$ - hydraulic power input of the pumping system, MW;

Hydraulic power input in its turn is estimated according to the formula from the hydraulics course:

$$
N=1,11 P d_{0}^{2} \mu \sqrt{\frac{P}{\rho}},
$$

where $P$ - mortar pressure at the pipe, MPa; $d_{0}$ - diameter of the jet-forming pipe, $\mathrm{m} ; \mu$ - coefficient of discharge through the pipe (in our case $\mu=0,75$ ); $g$ - free fall acceleration, $\mathrm{m} / \mathrm{s}^{2} ; \rho$ - density of water concrete suspension, $\mathrm{kg} / \mathrm{m}^{3}$.

Experimental research on the laboratory bench resulted in functional correspondence for estimation of instrument movement rational speed, corresponding to minimal power consumption and maximal speed of volume expansion of the rock mass being fastened:

$$
V_{\text {pau }}=0,01 \frac{P^{0,05} d_{0}^{0,03}}{C^{0,03}}
$$

And also a generalized formula for estimation of the depth of the fastened mas:

$$
h=0,17 \frac{d_{0}^{1,2} P^{1,2}}{V^{0,4} C^{0,3}}
$$

This way the resulting correspondences allows reasonable setting of constructional equipment parameters for road surface fastening by means of waterjet cementation and of technological modes of equipment operation, providing the needed process parameters.

The source of the water concrete suspension in its turn includes the following elements:

- high pressure cementing pump;

- mixing station.

All of these elements are joined with the help of pipeline system.

Taking into account that jet destruction and mixing of rock requires high kinetic energy of the water concrete jet, we need to use a powerful high pressure cementing pump to fasten rock masses. Analysis off literature and our own results show that the pump pressure should be 40-60 MPa.

Equipment, fully complying with the technological requirements, is now series-produced in Russian as well as in foreign industry.

For the realization of the idea of road surface fastening by means of waterjet cementation a sketch design of the cementing machine represented on Figure 8 was made.
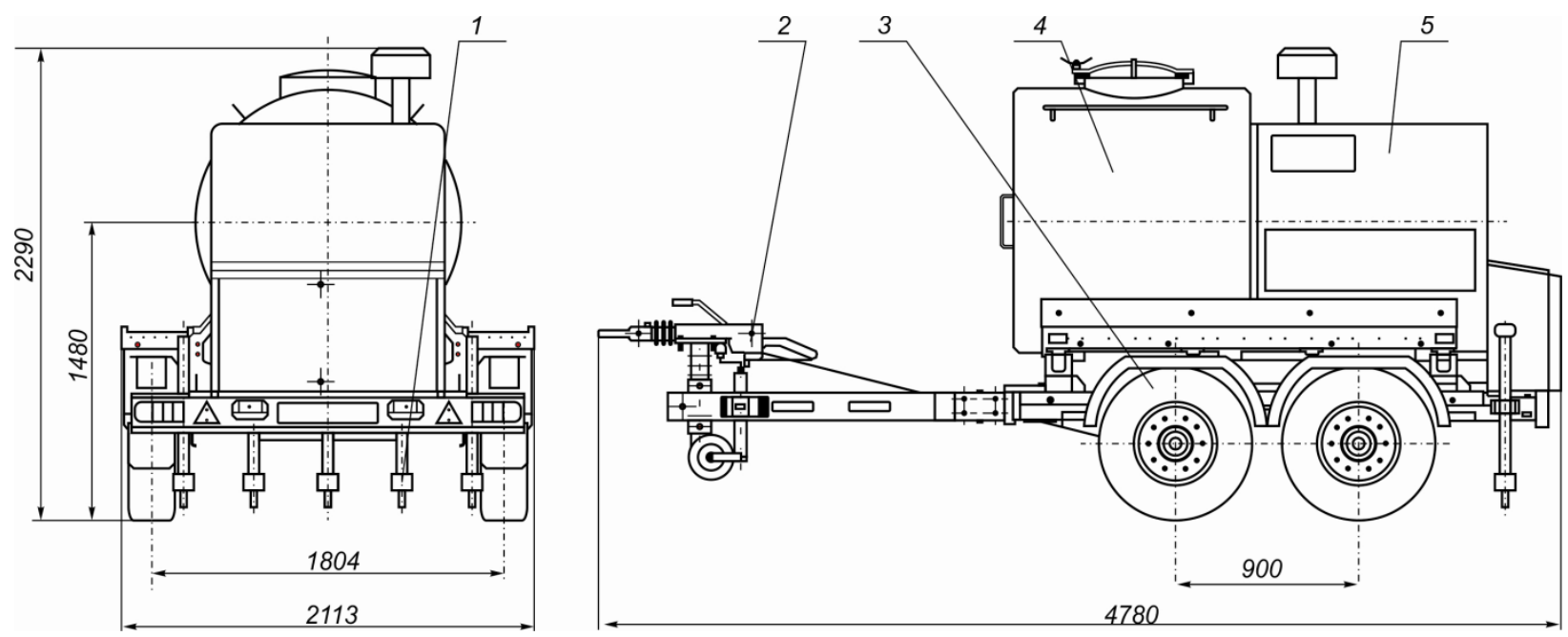

Figure 8. Cementing waterjet machine CHJM-1 
Cementing waterjet machine is a device, consisting of a mixer tank for water concrete mortar 4 and diesel engine pump system 5 assembled on the car trailer 3 . Diesel engine pump system 5 , taking the water concrete mortar from the mixer tank 4 transmits power to manifold 1 consisting of five waterjet instruments, directly working on the road surface. Universal device 2 provides junction between the machine and all kinds of construction, road construction and universal equipment.

Waterjet cementation of road surface is carried out with the help of one or multiple run of the waterjet cementation machine WCM-1 on the area being fastened.

\section{Conclusion}

Thus, the use of the suggested equipment during the construction of new highways and full repair of the existing ones guarantees the efficient use of resources due to the machine's operation within the range of sustainable parameters of the main constructional and operating conditions, found in preliminary bench and full-scale tests, and also due to the mathematical modeling of the process within a wide range of factors' change.

Development of Russian equipment for waterjet cementation of the road surface, that has no comparable counterparts in other countries, allows significant simplification of modern major highway construction technology by avoiding geowebs which are difficult to mount and with performance properties remaining at the same level.

Introduction of waterjet cementation in road construction widens further fields of use of jet technologies, which provide the efficient implementation of advanced knowledge-intensive technological solutions of a new qualitative level.

This article was written within the framework of the President Grant for Government Support of Young Russian Candidates of Science (№14.Z56.14.1983-MK) for 2014-15.

\section{References}

Abramovich, G. N. (1960). Theory of turbulent jets. Moscow: Fizmatgiz.

Brenner, V. A., Golovin, K. A., \& Pushkarev, A. E. (2007). Development of equipment for strengthening of unstable rock masses by means of water jet cementation. Tula: TSU Publishing House.

Brenner, V. A., Pushkarev, A. E., Zhabin, A. B., Antipov, V. V., \& Shchegolevsky, M. M. (1998). September 21-23). Upon the development of water jet technology. Technology and Mechanization of Mining. Jubilee volume dedicated to V.A. Brenner's 70 birthday anniversary, 17-24.

Broid, I. I. (2004). Water jet technology: Coursebook. Moscow: Association of construction universities.

Bulychev, N. C. (1994). Mechanics of underground constructions. Moscow: Nedra.

Fedorov, B. S., \& Petrosyan, L. R. (1983). Use of high-pressure jets in foundation works in the North. Foundation engineering and soil mechanics, 2, 19-21.

Garbuz, G. D. (1975). Study of interactions between high-speed jet and coal mass under slatted scheme of destruction. Moscow: A.A. Skochinsky Institute of Mining.

Golovin, K. A., Pushkarev, A. E., \& Kovalev, R. A. (2008). Upon the implementation of waterjet cementation of rocks in mining. Mining Journal, 6, 60-63.

Hashish, M. (1998). The waterjet as a tool. BHR Group Conference Series, 32.

Korolev, V. M., Smirnov, O. E., Argal, E. S., \& Ashikhmen, V. A. (2006). Experience with microcement stabilization of soils. Soil Mechanics and Foundation Engineering, 43(4).

Kovalev, R. A., \& Afonsky, I. V. (2013). Upon the fastening of road surface construction. Transport Construction, $11,4-6$.

Kuzmich, I. A., Bruns, S. A., \& Garbuz, G. D. (1972). Upon water jet destruction of coals and rocks. Moscow: Academy of Sciences of USSR.

Malinin, G., \& Gladkov, I. L. (2011). Investigation of the diameter of soil - cement columns under various soil conditions. Soil Mechanics and Foundation Engineering, 48(3), 11.

Nikonov, G. P., Kuzmich, I. A., \& Goldin, Y. A. (1986). Destruction of rocks with high-pressure water jets. Moscow: Nadra.

Nikonov, G. P., Kuzmich, I. A., \& Goldin, Y. A. (1986). Destruction of rock by means of high-speed jets. Moascow: Nedra. 
Nurok, G. A. (1979). Processes and technology of oper hydraulic mining. Moscow: Nedra.

Pettit, P. (1988, August). Jet grouting: the pace quickens. Civil engineering, 8, 65-68.

Pykhteev, G. N. (1996). General and major boundary problems of flat jet steady flows and their non-linear equations. Applied Mechanics and Technical Physics, 1, 32.

Rzhevsky, V. V., \& Novik, G. Y. (1984). Fundamentals of petrophysics. Moscow: Nedra.

Sammers, D. A. (1995). Waterjetting Technology. Oxford: Alden Press.

Shavlovsky, S. S. (1979). Fundamentals of jet dynamics during rock destruction. Moscow: Nauka.

Sližytė, D., \& Medzvieckas, J. (2013). Evaluation of Gravity Retaining Walls from Jet Grouting Piles Installed in Sands. Procedia Engineering, 57, 1070-1077. http://dx.doi.org/10.1016/j.proeng.2013.04.135

Tsytovich, N. A., \& Martirosyan, Z. G. (1981).Fundamentals of applied geomechanics in construction. Moscow: Vysshaya shkola.

Ukhov, S. B., Semenov, V. V., \& Znamensky, V. V. (2002). Mechanics of subsoil, bases and foundations: course book. Course book for constructors from specialized universities. Moscow: Vysshaya shkola.

\section{Copyrights}

Copyright for this article is retained by the author(s), with first publication rights granted to the journal.

This is an open-access article distributed under the terms and conditions of the Creative Commons Attribution license (http://creativecommons.org/licenses/by/3.0/). 